\title{
Weapons of Mass Destruction Technology Evaluation and Training Range
}

\section{IEEE International Conference on Technologies for Homeland Security}

\author{
Kevin L. Young
}

May 2009

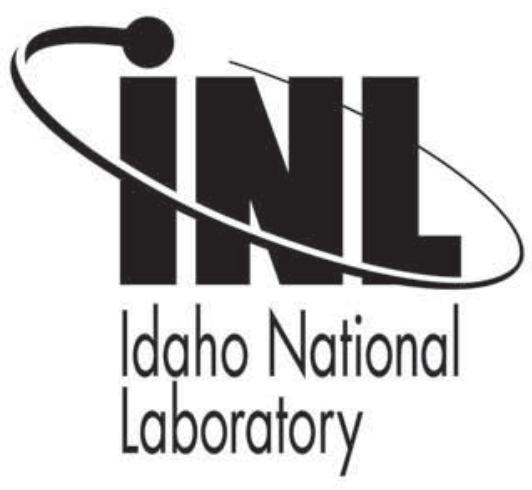

This is a preprint of a paper intended for publication in a journal or proceedings. Since changes may be made before publication, this preprint should not be cited or reproduced without permission of the author. This document was prepared as an account of work sponsored by an agency of the United States Government. Neither the United States Government nor any agency thereof, or any of their employees, makes any warranty, expressed or implied, or assumes any legal liability or responsibility for any third party's use, or the results of such use, of any information, apparatus, product or process disclosed in this report, or represents that its use by such third party would not infringe privately owned rights. The views expressed in this paper are not necessarily those of the United States Government or the sponsoring agency. 


\title{
Weapons of Mass Destruction Technology Evaluation and Training Range
}

\author{
Kevin Larry Young, Idaho National Laboratory, Idaho Falls, Idaho, KevinL.Young@INL.gov \\ STI Number: INL/CON-09-15657
}

\begin{abstract}
The Idaho National Laboratory (INL) has a long history for providing technology evaluation and training for military and other federal level Weapons of Mass Destruction (WMD) response agencies. Currently there are many federal organizations and commercial companies developing technologies related to detecting, assessing, mitigating and protecting against hazards associated with a WMD event. Unfortunately, very few locations exist within the United States where WMD response technologies are realistically field tested and evaluated using real chemical, biological, radiological, nuclear and explosive materials. This is particularly true with biological and radiological hazards. Related to this lack of adequate WMD, multi-hazard technology testing capability is the shortage of locations where WMD response teams can train using actual chemical, biological, and radiological material or highly realistic simulates. In response to these technology evaluation and training needs, the INL has assembled a consortium of subject matter experts from existing programs and identified dedicated resources for the purpose of establishing an all-hazards, WMD technology evaluation and training range. The author describes the challenges associated with creating the all-hazards WMD technology evaluation and training range and lists the technical, logistical and financial benefits of an all-hazards technology evaluation and training range. Current resources and capabilities for conducting allhazard technology evaluation and training at the INL are identified. Existing technology evaluation and training programs at the INL related to radiological, biological and chemical hazards are highlighted, including successes and lessons learned. Finally, remaining gaps in WMD technology evaluation and training capabilities are identified along with recommendations for closing those gaps.
\end{abstract}

\section{INTRODUCTION}

This paper describes the formation of a consolidated Weapons of Mass Destruction (WMD) technology evaluation and training range and the comprehensive set of resources and capabilities at the Idaho National Laboratory (INL) associated with conducting WMD-related work for Department of Homeland Security (DHS) and other federal agencies.
There are two main sections. The first section provides a description of unique resources and a background of existing WMD-related technology evaluation and training projects at the INL. This section will familiarize the reader with the variety of resources and capabilities available at the INL for WMD-related technology evaluation and training. This will provide the necessary framework for establishing the case for managing WMD technology evaluation and training projects within a single program.

The second section of the body specifies the benefits of combining WMD technology evaluation and WMD training projects within a single program. Specifically, technical, logistical, and financial benefits are given. This section also identifies the many challenges a large organization faces when consolidating several similar projects managed by separate departments into a coordinated program.

In the conclusion gaps in our country's WMD-related technology evaluation and training capabilities, such as an all-hazards collapsed structure training facility, are identified with proposed solutions for closing those gaps.

\section{WMD TECHNOLOGY EVALUATION AND}

\section{Training CAPABILITIES AT THE INL}

The INL is one of several research and development laboratories within the Department of Energy (DOE) and stands out as a unique national and international resource. In the early days, INL was known as the National Reactor Testing Station. Since 1949, over 52 mostly first-of-theirkind reactors were designed and built at the lab creating the largest concentration of reactors in the world. Today, the lab's primary mission continues to focus on advanced civilian nuclear technology research and development. The lab also has a very strong secondary mission related to supporting national security.

Resources and capabilities at the INL make it a natural location for supporting national security programs under the Department of Homeland Security (DHS), Department of Defense (DoD), and several other federal organizations. These resources and capabilities include: 
- 570,000 acres of remote terrain, isolated from major population centers.

- an isolable distribution substation for testing supervisory control and data acquisition (SCADA) security features.

- a radiological dispersal device (RDD) training program.

- a communications test bed, situated in a very low ambient radio frequency environment.

- an explosives test range capable of handling charge weights of up to 20,000 pounds TNT.

- a robotics research division specializing in robotic autonomy and sensor platform integration.

- a live fire test range capable of firing light antitank weapon (LAW) rockets and rocket-propelled grenades (RPGs).

- an unmanned aerial vehicle (UAV) range complete with runway and Federal Aviation Administration (FAA) cleared air space.

- several prototyping and fabrication facilities,

Some of these resources and capabilities and how they are used to support homeland security technology development and training are explained in further detail.

\section{0,000 Acres of Remote Terrain}

Geographically, the INL is the largest of all the research and development laboratories within the DOE. The laboratory is located in southeast Idaho and occupies a space approximately the size of Rhode Island. INL headquarters is centered in the town of Idaho Falls with most of the research facilities located west of town.

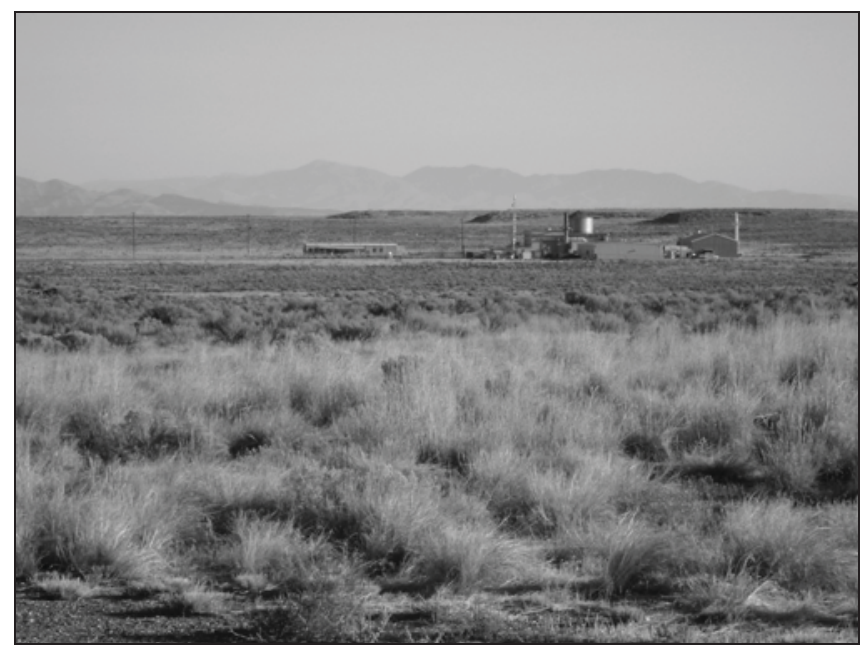

Figure 1 - A Small Section of the Idaho National Laboratory

The open, sparsely populated, high-desert environment, shown in Figure 1, provides a favorable setting for testing explosives, wireless equipment, UAVs, radiological equipment, and a variety of kinetic type weapons. The isolation and access controlled terrain also makes the INL an excellent location for conducting classified testing and training.

\section{Electric Grid}

The INL has its own electric power grid, consisting of seven substations, including one station that can be isolated from the commercial sector for testing security equipment and techniques that a public utility would not feel comfortable conducting due to risk of service interruption. INL scientists and engineers are also working jointly with private electric utilities to increase cyber security standards and technologies within SCADA systems to make them less vulnerable to terrorist attack. An engineer is shown in Figure 2 at one of INL's seven substations.

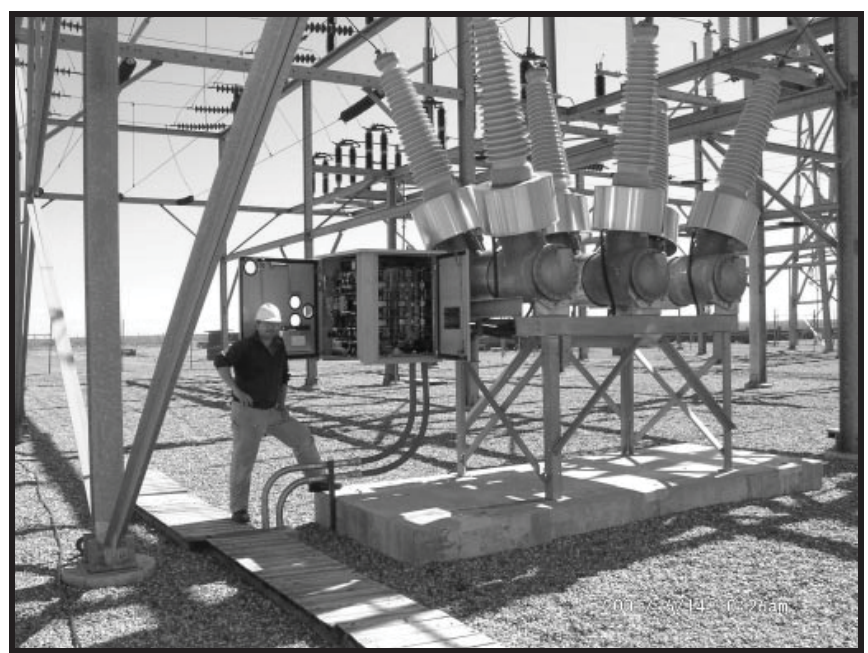

Figure 2-One of Seven INL Electric Substations

In addition to SCADA testing, the power grid provides a test bed for testing power line security devices such as the Transmission Line Security Monitor. This device senses and identifies threats, then alerts power system operators to protect these valuable assets and take action to prevent damage. The monitors mount directly on high-voltage lines ranging from $230 \mathrm{kV}$ to $500 \mathrm{kV}$ near each support tower. Using wireless communications to monitor and relay realtime threat information from tower to tower, these advanced sensors can detect tampering from sources such as unbolting tower support structures, the use of cutting torches and saws, shooting of conductors and insulators and explosive blast events.

\section{Radiological Dispersal Device (RDD) Training Program}

The use of radioactive contamination intentionally dispersed in a highly populated area by terrorists is a threat countries around the world take seriously. The most detrimental 
effects of an RDD event would be public panic and economic impact. According to the Department of Homeland Security, Federal Emergency Management Agency (FEMA) "In most plausible scenarios, the radioactive material would not result in acutely harmful radiation doses, and the primary public health concern from those materials would be increased risk of cancer to exposed individuals." [1] Even though the actual health concerns to humans from an RDD event are relatively low, the expected public fear and costly cleanup make it an issue that demands attention and preparation. The INL plays a vital role in assuring proper preparation of organizations responsible for dealing with an RDD event. INL's unique combination of radiological expertise, nuclear material, and facilities are utilized in the RDD Training Program.

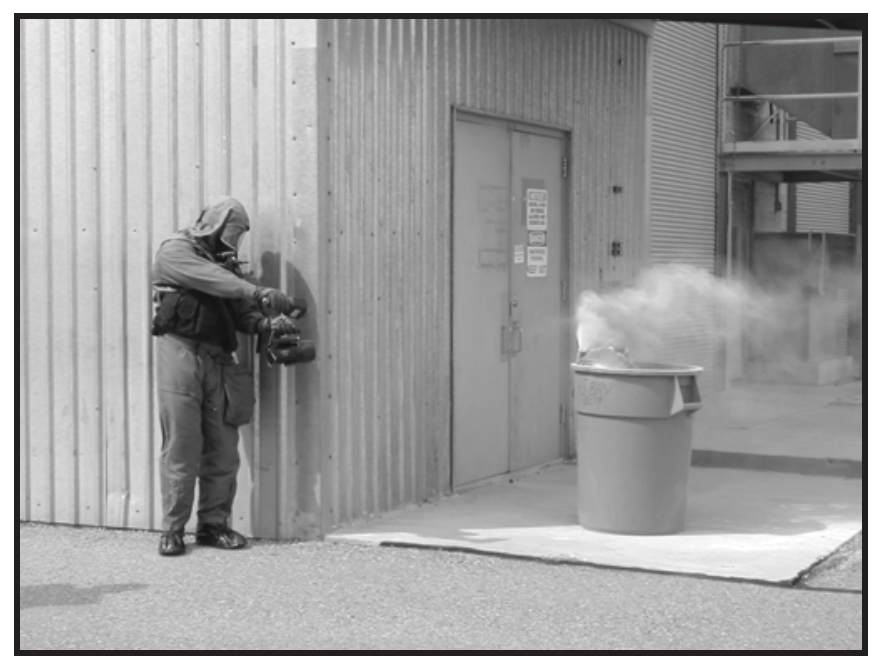

Figure 3 - National Guard Bureau Responder During INL RDD Training

Several special response groups from the U.S. Army, National Guard Bureau, Department of Energy, Department of Homeland Security, and U.S. Air Force have benefitted from this training program. Figure 3 shows a responder from the National Guard Bureau during an INL RDD training exercise.

\section{Communications Test Bed}

The Idaho National Laboratory was granted an Experimental Station License from the National Telecommunications and Information Administration enabling radio frequency experiments and training across a very wide Radio Frequency spectrum on a noninterference basis with other RF operators. Combining this with INL's large, isolated test and development range, INL provides a unique national resource enabling full-scale research, test, and evaluation of developmental communications systems, as well as the development of tactics and training for existing communications systems. Assets include lab and full-scale networks, two independent fiber loops (170 and
65 miles), both mountaintop and ground-based towers and facilities, and anechoic chamber and RF test labs, GSM 2.0, UMTS, CMDA, VOIP, and Mobile WiMax networks. These facilities, coupled with INL communication specialists, provide a full emersion research and test bed for vulnerability assessments, full-scale exercises and training, developmental testing, system integration, and application/device testing. Figure 4 shows one of several experimental communications towers on the INL.

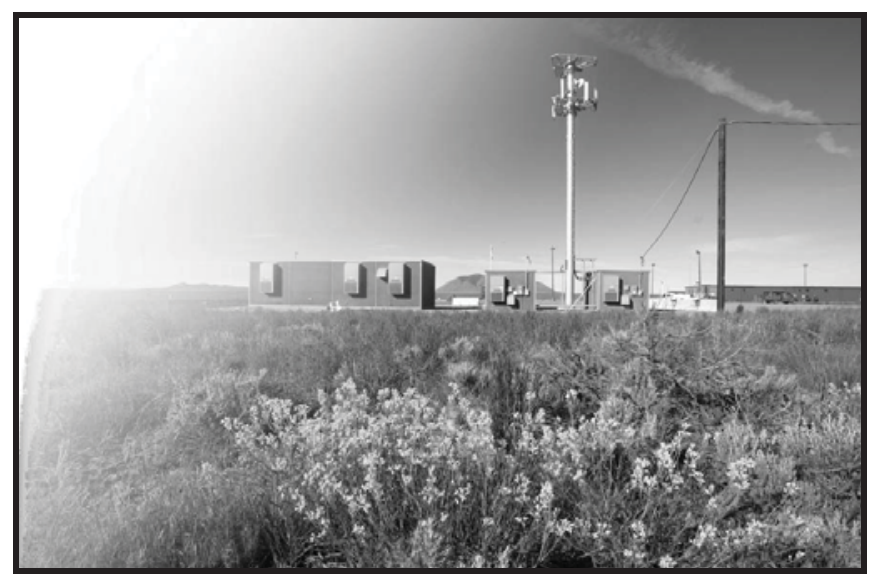

Figure 4 - Experimental Cell Tower at INL

Rapid recovery of cell phone service after a man-made or natural disaster is just one project currently making use of the Communications Test Bed.

\section{Explosives Test Range}

INL has a long history of explosive effects testing and research to protect Department of Energy critical assets. This research involves identifying vulnerabilities in existing or planned facilities, developing mitigative strategies to correct these vulnerabilities and implementing protective strategies. A combination of high-performance computing and explosive testing is used to design and validate these strategies.

In addition, INL has the capabilities to test a wide range of explosives threats for other federal agencies, law enforcement and private industry. Comprehensive testing with tools such as high-speed visual and infrared video capability allows the measurement of explosive effects on structures and protective barriers and to evaluate the effectiveness of potential countermeasures.

Testing of explosives detection equipment is a vital component of the INL explosives test range. Figure 5 shows the full-scale prototype of the Idaho Explosives Detection System (IEDS) that can detect explosives in a mid-size truck within 5 minutes. IEDS was successfully demonstrated in June 2004 at the INL where it detected real 
explosives (a mixture of PETN and C4). IEDS was again successfully demonstrated in July 2004 at Andrews Air Force Base where it detected ANFO within 5 minutes.

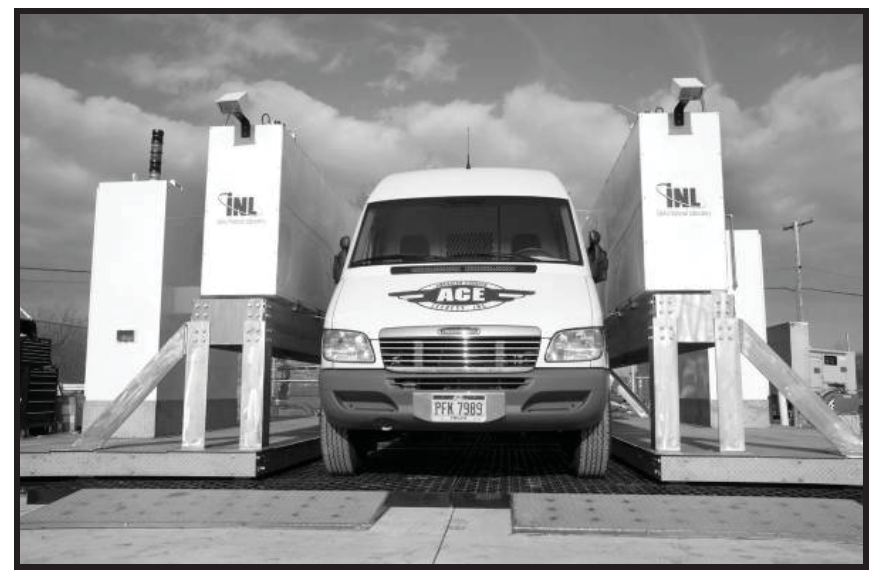

Figure 5 - Idaho Explosives Detection System

At both demonstrations the system correctly identified a truck containing no explosives. From November 2005 through February 2006 extensive measurements using the IEDS were performed for The Department of Homeland Security. [2]

INL's explosives test range is staffed by some of the world's most renowned explosives and materials experts who conduct scalable performance testing and develop advanced technologies to protect the United States against threats like vehicle-borne improvised explosive devices and rocket-propelled grenades. INL explosives engineers have more than 250 years of experience in the field and many have specialized military or doctoral degree educations.

\section{Robotics}

INL's robotics group has contributed towards several advances in providing reliable robotic performance. They have also conducted several technology evaluations of robotic platforms and integrated sensors for DHS. One area of research involves integrating components of robot intelligence. This work addresses the fundamental challenges of mobile robot autonomy by developing and testing the following tasks:

- Accurate positioning and map-building

- Long-range, adaptive communication

- Reactive obstacle avoidance and path planning

- High-speed waypoint navigation without GPS

- Self-status awareness and health monitoring

- Ability to accomplish high-level tasking

The goal is not to provide human-like intelligence for the robot, but rather to end up with intrinsic behavior analogous to that of a trained police dog. [3] A robot platform with integrated laser mapping system is shown in Figure 6.

\section{Live Fire Test Range}

The INL live fire test range originated out of necessity to help train the DOE protective forces responsible for guarding nuclear material. Today, the live fire test range, which is located on 330 acres of desert terrain, consists of eight indoor and outdoor ranges and tactical training facilities.

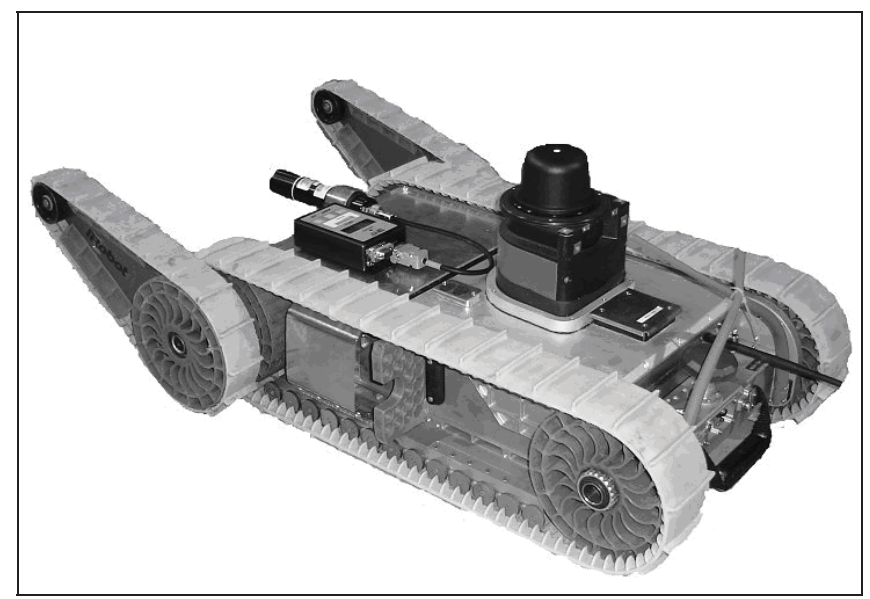

Figure 6 - Robot Platform with Integrated Laser Mapping System

It provides for the testing of handguns, rifles, and heavy weapons; such as machine guns, precision rifles, grenade launchers and shoulder-fired, anti-armor weapons. The range also allows for explosive training and testing, including explosive breaching of doors and other barriers.

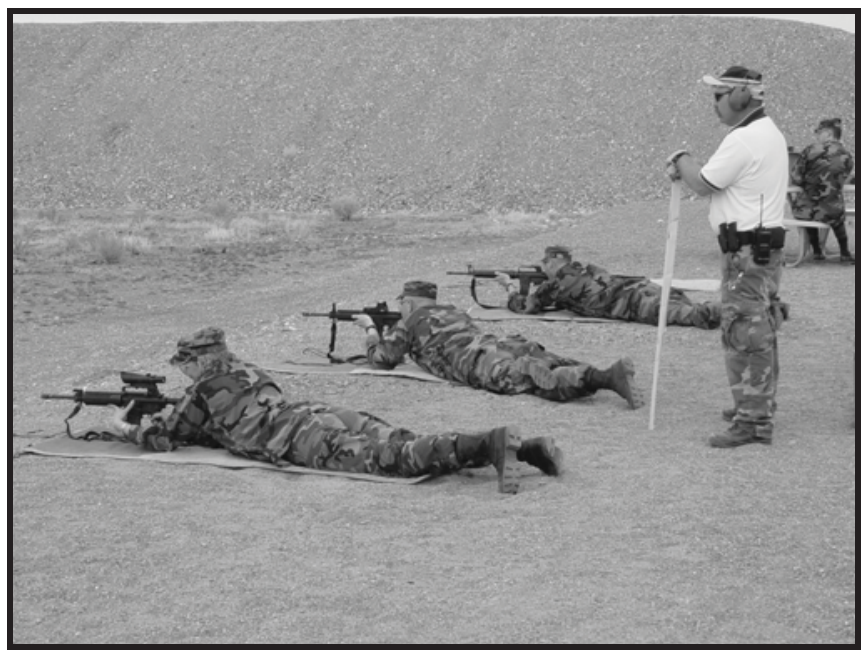

Figure 7 - National Guard Bureau Responders Train at INL Live Fire Test Range

Every year a variety of organizations within DHS and DoD use the INL live fire test range to hone their skills and test 
new technologies. Figure 7 shows a group of National Guard Bureau responders training on the INL Live Fire Test Range.

\section{Unmanned Aerial Vehicle (UAV) Range}

With its access-controlled space, high-desert terrain and sparse population, INL is in a unique position to offer unmanned aerial vehicle and unmanned ground vehicle collaborative operational testing and demonstration.

INL's UAV program focuses on unique applications and missions for a wide variety of customers. The INL UAV program includes small, hand-launched systems, unmanned rotorcraft and larger UAV craft. The larger craft weigh approximately 55 pounds and can carry up to 20 pounds. A larger payload, combined with longer flight times, enables these aircraft to perform more complex and beneficial missions.

INL possesses numerous UAV payload packages and ground-control supported equipment. The laboratory maintains a dedicated UAV 1000' x 100' airfield and tactical support facility. INL UAV personnel have demonstrated their operations expertise by simultaneously flying five small UAVs autonomously in the same confined airspace. Figure 8 shows INL personnel preparing a UAV for testing at INL UAV flight range. UAVs are used throughout several mission areas of homeland security. Border patrol, reconnaissance, search and rescue, and consequence management are a few areas in which UAVs are being utilized.

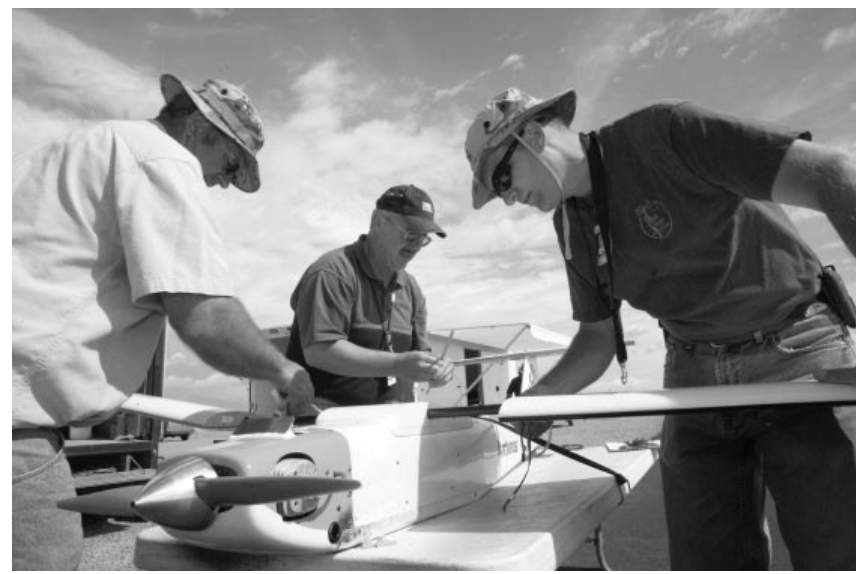

Figure 8 - INL UAV Personnel Prepare a UAV for Testing

As part of INL's First Responder UAV project in support of homeland security, the INL has analyzed, designed, prototyped, integrated, and tested a dynamic tracking directional antenna to support high gain robust communications from a static ground station to a dynamic airborne UAV possessing a small omni-direction antenna. [4] This successfully tested technology allows UAVs to operate farther from a static ground station with a low power transmitter.

\section{Rapid Prototyping}

Modern day threats to homeland security are keeping pace with the rapid development of technology. Government agencies can no longer afford the traditional, multi-year technology development cycle time line. Homeland security technologies must be quickly developed from basic research or must be adapted from technologies existing in the commercial sector. The INL has developed a rapid prototyping capability that has proven successful in meeting emerging homeland security technology needs. The rapid prototyping process adapts existing commercial technology or takes newly developed government technology at the end of its research phase and rapidly moves it through the development and deployment phases.

The function of rapid prototyping requires a team of multiskilled technicians, multi-function machine shop facilities, and an efficient procurement system.

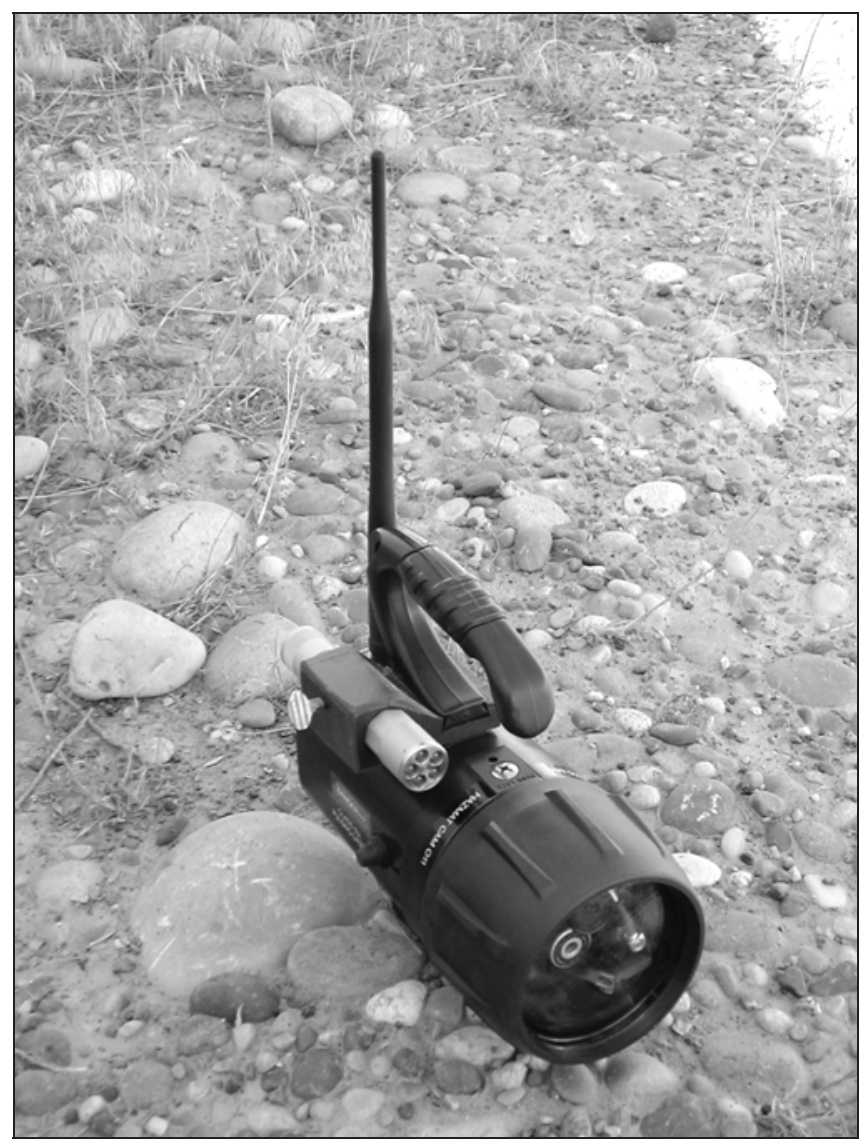

Figure 9 - Hazmat Cam Wireless Video System

Examples of equipment rapidly developed at the INL for homeland security include the Mobile Munitions Assessment System (MMAS), used to rapidly and safely 
assess the contents of munitions or improvised explosive devices (IEDs); the Hazmat Cam Wireless Video System, shown in Figure 9, used for providing real-time tactical video for incident commanders during a hazardous response [5], and the Timed Tactical Firing Device (TTFD) used to safely, accurately, and inexpensively detonate explosive charges. Each of these technology development and deployment projects took less than one year from concept to delivery.

\section{Benefits AND Challenges of CoMbining WMD-RELATED TECHNOLOGY EVALUATION}

\section{and Training Projects}

WMD technology evaluation and WMD training are two synergistic efforts sharing a common resource set and customer base. Until recently, the majority of these efforts have been individual in nature and managed by a variety of different departments within the INL. In many cases these capabilities have existed at the INL long before the more recent increased focus on homeland security. In the past, requests for specific training or technology evaluation were treated as individual projects. With the increased focus on homeland security, the number of such requests has grown to a point where treating each as a separate project is inefficient from a resource allocation and management perspective. By consolidating these common efforts under a single management structure with shared resources, logistical complexity is reduced resulting in cost savings. An additional benefit is an increase in business opportunities through greater awareness and connectivity of the entire WMD-related customer base and WMD-related capabilities at the INL.

There are many challenges associated with consolidating several similar projects managed by separate departments into a common program. These challenges are described along with methodologies for overcoming those challenges. Once the challenges are overcome, the technical, logistical, and financial benefits for consolidating can be realized.

The brainstorming effort to form a strategy for consolidating programs provided a perfect opportunity to consider WMD technology evaluation and training needs not currently met by existing programs. This section of the paper describes the benefits and challenges for consolidating WMD technology evaluation and training activities at the INL. The paper concludes with a brief description of identified gaps and proposed solutions for closing those gaps.

\section{The Need to Consolidate WMD-related Projects}

Many of the capabilities and resources listed in Section 2 have existed at the INL for a long time. These assets were controlled by several different programs with typically distinct customers. Only occasionally did the same customer group overlap into multiple INL program areas. After the 2001 terrorist attacks on the United States, there was a significant increase in demand of resources and capabilities at the INL to quickly meet the rapidly growing homeland security technology and training needs.

Special response groups such as the National Guard Bureau Weapons of Mass Destruction Civil Support Teams (WMDCSTs) were formed to address the increased threat from WMD terrorist attacks on the U.S. These teams consist of well equipped, multi-hazard emergency responders. They, like several other federal organizations, were coming to the INL to receive specialty training, perform validation of newly developed equipment, and practice their standard operating procedures through scenario-based field exercises.

To efficiently and effectively meet these increasing requests for WMD training and WMD technology evaluation, the INL is evaluating its approach towards executing these activities. The old method of accepting a WMD-related training or technology evaluation request and then going through the effort of adapting existing program resources and capabilities to meet that request is expensive and time consuming. In addition, the method often requires the same customer to initiate several separate projects with the INL to obtain their training and technology evaluation needs. This multi-project approach increases the possibility for confusion and additional overhead expense.

Another problem encountered by INL project managers is competition for similar resources. WMD-related technology evaluation and training projects typically require similar facilities, radioactive material, and experienced personnel in the fields of radiological, biological, and chemical hazards. Without a consolidated management approach to allocate these limited resources, and the demand for such resources rapidly growing, project managers often find themselves in the difficult position of obtaining adequate resources to complete their projects.

\section{Benefits from Consolidating}

The benefits obtained by consolidating the management approach for WMD-related technology evaluation and training programs can be considered three ways: logistically, technically, and financially.

Logistical Benefits-Logistical benefits of consolidating similar WMD-related projects are obtained by sharing a common pool of resources, utilizing common facilities for both technology evaluation and training, and combining 
WMD technology evaluation projects with WMD training efforts. The key point to keep in mind here is WMD response organizations that require specialty training are the same group of people who are most effective at evaluating new or enhanced WMD response technology.

Technical Benefits-Technical benefits of consolidating similar WMD-related projects are realized by both the customer and providing agency. The primary benefit is enhanced knowledge resulting from looking at the execution of WMD-related technology evaluation and training holistically. With technology-heavy groups such as WMD responders, new technology drives changes to standard operating procedures which require new training. The need for new technology is frequently identified during realistic, scenario driven training. By engaging directly in both activities, the technical expertise of the provider and customer are enhanced.

Financial Benefits-The financial benefits for consolidating WMD-related projects can be substantial. Efficiency equals cost savings for both the provider and the customer. WMDrelated projects require rigorous safety and environmental review and approval. A consolidated management approach to these projects allows for combining the safety review and approval of multiple WMD projects significantly reducing the number of labor hours associated with this activity. A commonly managed group of test and training specialists can be cross-trained and more effectively resource loaded across the entire scope of projects reducing labor costs. From a new business perspective, consolidation will lead to increased business. Since the most likely source of new business is from existing customers, consolidating resources and capabilities increases the opportunities for an existing customer to learn about other related capabilities and resources leading to new business opportunities.

\section{Challenges of Consolidating}

A significant challenge of consolidating WMD technology evaluation and training projects at the INL involves reviewing and changing the existing management methods for conducting this work. Existing management methods start with a project request and then apply available resources. This method makes it very hard to forecast future growth and ensure adequate resource loading. In order to overcome this challenge, the INL has assembled a consortium of subject matter experts from existing WMD programs and has initiated the process of identifying a set of common, dedicated resources for the purpose of WMD technology evaluation and training projects. This consortium is also developing concepts and potential management methods to ensure common resources are utilized efficiently.

\section{Conclusions}

INL's existing programs and capabilities in SCADA testing, RDD training, wireless testing, explosives testing, robotics, live fire test range, unmanned aerial vehicles, and rapid prototyping provide several unique, national assets needed for WMD related training and technology evaluation. The INL, in response to the increasing need for these assets, has initiated the process of evaluating the consolidation of related WMD training and technology programs. The effort was initiated with the expectations of reducing the logistical and technical complexity of managing multiple programs for similar customers. The resulting efficiencies translate to cost savings for both the provider and customer.

The process of assessing existing WMD-related capabilities and resources against homeland security technology evaluation and training needs provided insight into capabilities currently not available in the United States, yet desired by homeland security organizations. For example, a single training location capable of using radiological, biological, and chemical hazards simultaneously does not exist.

INL's long held expertise in radiological science and explosives testing along with their emerging capabilities in the areas of chemical and biological science provide an opportunity to create the first true all-hazards technology evaluation and training range.

A more specific need in our country's WMD-related training capabilities is the need for a collapsed structure training facility capable of accommodating short half-life radioactive contamination. There is a need for emergency responders to train in a collapsed structure environment with radiological hazards. Facilities for conducting this type of training are very limited and a detailed bestpractices course does not currently exist.

The development of best-practices courses and a realistic, all-hazards training facility, will allow emergency responders to develop the skills and confidence needed for all phases of response to a incident involving radiological hazards, from search and extraction of survivors to site clean-up.

The process of fine tuning the consolidated management approach for WMD-related projects at the INL is still in progress, but the benefits of consolidating in terms of logistical, technical, and financial efficiencies is evident.

\section{REFERENCES}


[1] Michael Chertoff, "Planning Guidance for Protection and Recovery Following Radiological Dispersal Device (RDD) and Improvised Nuclear Device (IND) Incidents," Docket ID FEMA-2004-0004, Z-RIN 1660-ZA02, Federal Register/Vol. 73, No. 149, August 1, 2008.

[2] Edward L. Reber, Larry G. Blackwood, Andrew J. Edwards, Ann E. Egger, Paul J. Peterson, "Idaho Explosives Detection System: Development and Enhancements," Sensing and Imaging, June 2006.

[3] David Bruemmer, David Gertman, Curtis Nielsen, R. Scott Hartley, Douglas Few, Recent Advances In Control Systems, Robotics and Automation, Third Edition, Volume 1, Palermo, Italy: Internationalsar, 2009.

[4] Matthew O. Anderson, Scott G. Bauer, James R. Hanneman, "Unmanned Aerial Vehicle (UAV) DynamicTracking Directional Wireless Antennas for Low Powered Applications that Require Reliable Extended Range Operations in Time Critical Scenarios," 2006 American Nuclear Society Meeting Proceedings, February 12 - 15, 2006.

[5] Kevin L. Young, "Hazmat Cam Wireless Video System," 2006 American Nuclear Society Meeting Proceedings, February 12 - 15, 2006. 